\title{
Greater Blood Pressure Variability Is Associated With Lower Cognitive Performance
}

Citation for published version (APA):

Zhou, T. L., Kroon, A. A., Sloten, T. T. V., van Boxtel, M. P. J., Verhey, F. R. J., Schram, M. T., Köhler, S., Stehouwer, C. D. A., \& Henry, R. M. A. (2019). Greater Blood Pressure Variability Is Associated With Lower Cognitive Performance: The Maastricht Study. Hypertension, 73(4), 803-811. https://doi.org/10.1161/hypertensionaha.118.12305

Document status and date:

Published: 01/04/2019

DOI:

10.1161/hypertensionaha.118.12305

Document Version:

Publisher's PDF, also known as Version of record

Document license:

Taverne

Please check the document version of this publication:

- A submitted manuscript is the version of the article upon submission and before peer-review. There can be important differences between the submitted version and the official published version of record.

People interested in the research are advised to contact the author for the final version of the publication, or visit the DOI to the publisher's website.

- The final author version and the galley proof are versions of the publication after peer review.

- The final published version features the final layout of the paper including the volume, issue and page numbers.

Link to publication

\footnotetext{
General rights rights.

- You may freely distribute the URL identifying the publication in the public portal. please follow below link for the End User Agreement:

www.umlib.nl/taverne-license

Take down policy

If you believe that this document breaches copyright please contact us at:

repository@maastrichtuniversity.nl

providing details and we will investigate your claim.
}

Copyright and moral rights for the publications made accessible in the public portal are retained by the authors and/or other copyright owners and it is a condition of accessing publications that users recognise and abide by the legal requirements associated with these

- Users may download and print one copy of any publication from the public portal for the purpose of private study or research.

- You may not further distribute the material or use it for any profit-making activity or commercial gain

If the publication is distributed under the terms of Article $25 \mathrm{fa}$ of the Dutch Copyright Act, indicated by the "Taverne" license above, 


\title{
Greater Blood Pressure Variability Is Associated With Lower Cognitive Performance The Maastricht Study
}

\author{
Tan Lai Zhou, Abraham A. Kroon, Thomas T. van Sloten, Martin P.J. van Boxtel, \\ Frans R.J. Verhey, Miranda T. Schram, Sebastian Köhler, Coen D.A. Stehouwer, Ronald M.A. Henry
}

Abstract-An increasing number of individuals will face age-related cognitive difficulties because life expectancy has increased. It is, therefore, important to identify modifiable risk factors for cognitive impairment. Very short-term to mid-term blood pressure variability (BPV) may be such a factor because it may cause cerebral ischemia. To this end, we investigated whether greater systolic and diastolic BPV are cross-sectionally associated with memory function $(\mathrm{n}=1804)$, information processing speed $(n=1793)$, and executive function $(n=1780)$ in 40- to 75-year-old individuals from The Maastricht Study. A composite BPV-index was derived by standardizing within-visit, 24-hour, and 7-day BPV. We performed linear regression with adjustments for age, sex, educational level, 24-hour systolic or diastolic pressure, and cardiovascular risk factors. We found that a 1-SD greater systolic BPV was not associated with information processing speed ( $\beta$ [SD difference], $-0.10 ; 95 \% \mathrm{CI},-0.14$ to 0.06 ), or executive function $(-0.09 ; 95 \% \mathrm{CI},-0.20$ to 0.02 ) but was marginally associated with lower memory function $(-0.11 ; 95 \% \mathrm{CI},-0.21$ to 0.00$)$. A 1-SD greater diastolic $\mathrm{BPV}$ was associated with lower information processing speed $(-0.10 ; 95 \% \mathrm{CI},-0.20$ to -0.00$)$ and executive function $(-0.12 ; 95 \% \mathrm{CI},-0.22$ to -0.01$)$ and marginally associated with lower memory function $(-0.09 ; 95 \% \mathrm{CI},-0.20$ to 0.01). These effects on cognitive performance are equivalent to $\approx 3$ additional years of aging. In conclusion, greater very short-term to mid-term diastolic and, to a lesser extent, systolic BPV may be a modifiable risk factor for cognitive deterioration in 40- to 75-year-old, community-dwelling individuals. (Hypertension. 2019;73:803-811. DOI: 10.1161/ HYPERTENSIONAHA.118.12305.) • Online Data Supplement

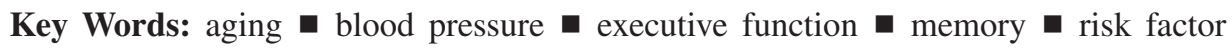

$\mathrm{L}$ ife expectancy has increased globally over the past decades, which implies that an increasing number of individuals will face cognitive difficulties or even dementia because of aging. ${ }^{1,2}$ It is, therefore, important to identify potential modifiable causes of cognitive impairment to prevent cognitive decline. We hypothesize that greater very short- to mid-term blood pressure variability (BPV) may be a modifiable $^{3}$ risk factor.

Greater BPV may contribute to lower cognitive performance by 2 mechanisms. First, the brain microvasculature has a relatively low microvascular impedance. Greater pulsatile pressure loads (ie, greater BPV) may, therefore, penetrate deeply into the vasculature, and hence lead to microvascular damage. ${ }^{4,5}$ Second, decreased perfusion may occur with (excessive) falls in blood pressure (BP), especially when cerebral autoregulation is impaired. ${ }^{6}$ Cerebral microvascular damage and falls in BP may, in turn, lead to ischemia, structural brain abnormalities, and ultimately lower cognitive performance.

Indeed, previous studies have suggested that greater BPV and lower cognitive performance are associated. ${ }^{7-16}$ However, these studies have focused mainly on long-term (ie, visit-tovisit) $\mathrm{BPV},{ }^{7-12}$ have targeted old to very old individuals, ${ }^{11-14}$ have evaluated cognitive performance by only a single, global test (eg, Mini-Mental State Examination), ${ }^{15-17}$ or did not adjust for important confounders, such as mean BP and use of antihypertensive medication. ${ }^{18,19}$

To address the issues stated above, we investigated the association between BPV along the very short- to mid-term range (ie, within-visit, 24-hour, and 7-day) BPV and 3 domains of cognitive performance (ie, memory function $[\mathrm{MF}]$, information processing speed [IPS], and executive function [EF]) in 40- to 75-year-old participants from the population-based Maastricht Study.

Received October 26, 2018; first decision November 5, 2018; revision accepted January 15, 2019.

From the Department of Internal Medicine (T.L.Z., A.A.K., M.T.S., C.D.A.S., R.M.A.H.), Department of Psychiatry and Neuropsychology, Alzheimer Centre Limburg (M.P.J.v.B., F.R.J.V., S.K.), and Heart and Vascular Centre (M.T.S., R.M.A.H.), Maastricht University Medical Centre, the Netherlands; CARIM School for Cardiovascular Diseases (T.L.Z., A.A.K., T.T.v.S., M.T.S., C.D.A.S., R.M.A.H.) and MHeNs School for Mental Health and Neuroscience (M.P.J.v.B., F.R.J.V., S.K.), Maastricht University, the Netherlands; Faculté de Médecine, Université Paris Descartes, Sorbonne Paris Cité, France (T.T.v.S.); and Department of Epidemiology and Department of Arterial Mechanics, INSERM, UMR-S970, Paris Cardiovascular Research Center, France (T.T.v.S.).

The online-only Data Supplement is available with this article at https://www.ahajournals.org/doi/suppl/10.1161/HYPERTENSIONAHA.118.12305.

Correspondence to Ronald M.A. Henry, Department of Internal Medicine, Maastricht University Medical Centre, P. Debyelaan 25, PO Box 5800, 6202 AZ, Maastricht, the Netherlands. Email rma.henry@mumc.nl

(C) 2019 American Heart Association, Inc.

Hypertension is available at https://www.ahajournals.org/journal/hyp 


\section{Methods}

\section{The Maastricht Study}

We used data from The Maastricht Study, an observational prospective population-based cohort study. The rationale and methodology have been described previously ${ }^{20}$ In brief, the study focuses on the etiology, pathophysiology, complications, and comorbidities of type 2 diabetes mellitus (T2DM) and is characterized by an extensive phenotyping approach. Eligible for participation were all individuals aged between 40 and 75 years and living in the southern part of the Netherlands. Participants were recruited through mass media campaigns and from the municipal registries and participants with T2DM through the regional Diabetes Patient Registry via mailings. Recruitment was stratified according to known T2DM status, with an oversampling of individuals with T2DM, for reasons of statistical efficiency. The present report includes cross-sectional data from the first 3451 participants. The examinations of each participant were performed within a time window of 3 months. The study has been approved by the institutional medical ethical committee (NL31329.068.10) and the Minister of Health, Welfare, and Sports of the Netherlands (Permit 131088105234-PG). All participants gave written informed consent. Data are available from The Maastricht Study for any researcher who meets the criteria for access to confidential data, and the corresponding author may be contacted to request data.

\section{Data collection}

\section{BP Measurements and BPV}

A detailed description of the office, 24-hour ambulatory, and 7-day home BP measurements and variability have been reported previously. ${ }^{21}$ Briefly, within-visit BPV was calculated as the SD of 3 consecutive office BP measurements, with a 1-minute interval, after 10 minutes of rest. Twenty-four hour BPV was calculated as the average real variability of BP readings taken every 15 minutes between 08:00 AM to 23:00 PM, and every 30 minutes between 23:00 PM to 08.00 AM, 7-day BPV was calculated as the SD of home BP measurements taken twice, with a 1-minute interval, each morning, and evening, for 7 consecutive days. We calculated a composite index of BPV of within-visit, 24-hour, and 7-day BPV, for reasons of statistical efficiency: first, it reduces the biological variability of each individual measure, ${ }^{22}$ as we hypothesize that the (patho)physiological mechanisms underlying the association between greater BPV and worse cognitive performance overlap. Second, it reduces the chance of a type I error. This approach is justified when the individual measures within a composite index all associate in the same direction with the outcome. ${ }^{23}$ The individual measures were standardized into $Z$ scores (individual value/population mean/population SD). The individual measures were then summed and averaged into the composite index of systolic and diastolic BPV.

\section{Cognitive Performance}

Cognitive performance was assessed by a concise (30-minute) neuropsychological test battery. ${ }^{20}$ For conceptual clarity, test scores were standardized and divided into 3 cognitive domains (ie, MF, IPS, and EF). A detailed description of neuropsychological tests and methods used to calculate domain scores is provided in the Methods in the online-only Data Supplement. Briefly, MF was evaluated using the Verbal Learning Test $^{24}$ by calculating the standardized average of total immediate and delayed recall scores. The composite score for IPS was derived from the Stroop Color-Word Test Part I and II, ${ }^{25}$ the Concept Shifting Test Part A and B,${ }^{26}$ and the Letter-Digit Substitution Test. ${ }^{27} \mathrm{EF}$ was assessed by the Stroop Color-Word Test Part III and the Concept Shifting Test Part C. If necessary, individual test scores were log-transformed to fulfill the normality assumption or inverted so that higher scores indicated better cognitive performance. After selection of the final study population, cognitive performance test scores were standardized again to maintain a mean of zero and SD of 1.

\section{Covariates}

Alcohol consumption, smoking status, educational level, history of cardiovascular disease (CVD), and moderate-to-vigorous physical activity were assessed by questionnaire. Alcohol consumption was defined as nonconsumer, low-consumer ( $\leq 7$ alcoholic drinks/wk for women; $\leq 14$ alcoholic drinks/wk for men), and high-consumer ( $>7$ alcoholic drinks/wk for women; $>14$ alcohol drinks/wk for men). Smoking status was categorized into never, former, and current smoker. Educational level was classified into 3 groups: low (none, primary or lower vocational education only), intermediate (intermediate general secondary, intermediate vocational or higher general secondary education), and high (higher vocational education or university level of education). Body mass index (BMI), waist circumference, total cholesterol, HDL (high-density lipoprotein) cholesterol,

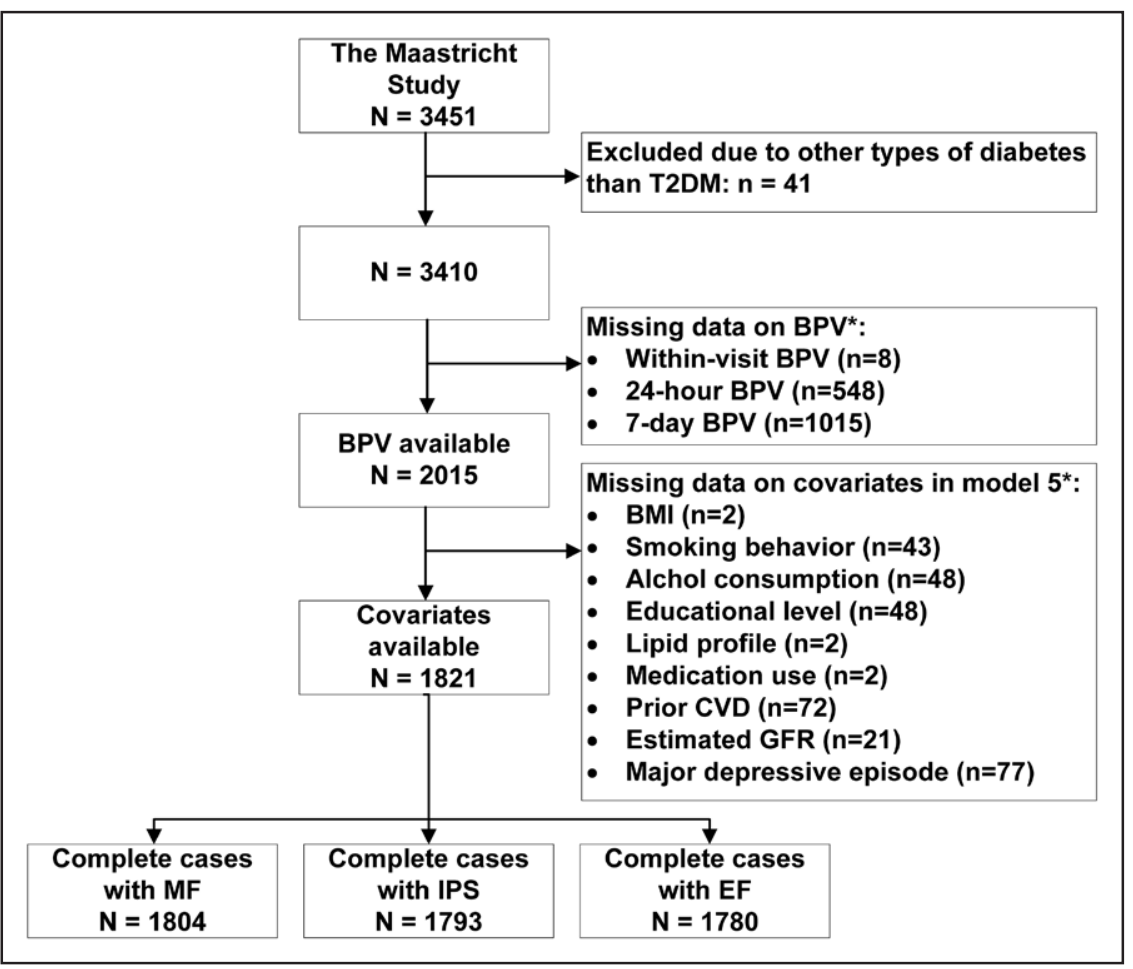

Figure 1. Flow diagram delineating the selection of the final study populations. $\mathrm{BMI}$, body mass index; BPV, blood pressure variability; CVD, cardiovascular disease; EF, executive functioning; GFR, glomerular filtration rate; MF, memory function; IPS, information processing speed; and T2DM, type 2 diabetes mellitus. *Not mutually exclusive. 
Table 1. Clinical Characteristics of the Study Population (With Complete Memory Function) According to Tertiles of Systolic Blood Pressure Variability

\begin{tabular}{|c|c|c|c|c|}
\hline \multirow[b]{2}{*}{ Characteristic } & \multirow{2}{*}{$\begin{array}{c}\text { Memory Function } \\
\text { Population, } n=1804\end{array}$} & \multicolumn{3}{|c|}{ Tertiles of Composite Systolic Blood Pressure Variability } \\
\hline & & Tertile 1 (Low), $\mathrm{n}=601$ & Tertile 2 (Middle), $n=602$ & Tertile 3 (High), $n=601$ \\
\hline \multicolumn{5}{|l|}{ Demographics } \\
\hline Age, y & $59.8 \pm 8.0$ & $57.7 \pm 8.6$ & $60.1 \pm 7.6$ & $61.5 \pm 7.6$ \\
\hline Men & $936(51.9 \%)$ & $323(53.7 \%)$ & $311(51.7 \%)$ & $302(50.2 \%)$ \\
\hline \multicolumn{5}{|l|}{ Educational level } \\
\hline Low & $287(15.9 \%)$ & $84(14.0 \%)$ & $105(17.4 \%)$ & $98(16.3 \%)$ \\
\hline Intermediate & $786(43.6 \%)$ & $260(43.3 \%)$ & $249(41.4 \%)$ & $277(46.1 \%)$ \\
\hline High & $731(40.5 \%)$ & $257(42.8 \%)$ & $248(41.2 \%)$ & $226(37.6 \%)$ \\
\hline \multicolumn{5}{|l|}{ Cardiovascular risk factors } \\
\hline $\mathrm{BMI}, \mathrm{kg} / \mathrm{m}^{2}$ & $27.0 \pm 4.3$ & $26.3 \pm 4.2$ & $26.9 \pm 4.1$ & $27.7 \pm 4.4$ \\
\hline \multicolumn{5}{|l|}{ Glucose metabolism status } \\
\hline Normal glucose metabolism & $1025(56.8 \%)$ & $395(65.7 \%)$ & $354(58.8 \%)$ & $276(45.9 \%)$ \\
\hline Prediabetes & $269(14.9 \%)$ & $84(14.0 \%)$ & $89(14.8 \%)$ & $96(16.0 \%)$ \\
\hline Type 2 diabetes mellitus & $510(28.3 \%)$ & $122(20.3 \%)$ & $159(26.4 \%)$ & $229(38.1 \%)$ \\
\hline Triglycerides, mmol// & $1.2[0.88-1.71]$ & $1.1[0.8-1.5]$ & $1.2[0.9-1.7]$ & $1.3[1.0-1.9]$ \\
\hline Total-to-HDL cholesterol ratio & $3.7 \pm 1.2$ & $3.7 \pm 1.2$ & $3.7 \pm 1.1$ & $3.8 \pm 1.2$ \\
\hline History of cardiovascular disease & $303(16.8 \%)$ & $85(14.1 \%)$ & $109(18.1 \%)$ & $109(18.1 \%)$ \\
\hline eGFR, $\mathrm{ml} /\left(\min \cdot 1.73 \mathrm{~m}^{2}\right)$ & $88.4 \pm 14.6$ & $90.6 \pm 14.4$ & $87.8 \pm 14.1$ & $86.6 \pm 15.1$ \\
\hline \multicolumn{5}{|l|}{ Lifestyle variables } \\
\hline \multicolumn{5}{|l|}{ Smoking behavior } \\
\hline Never & $646(35.8 \%)$ & $247(41.1 \%)$ & $186(30.9 \%)$ & $213(35.4 \%)$ \\
\hline Former & $937(51.9 \%)$ & $286(47.6 \%)$ & $336(55.8 \%)$ & $315(52.4 \%)$ \\
\hline Current & $221(12.3 \%)$ & $68(11.3 \%)$ & $80(13.3 \%)$ & $73(12.1 \%)$ \\
\hline \multicolumn{5}{|l|}{ Alcohol consumption } \\
\hline None & $342(19.0 \%)$ & $93(15.5 \%)$ & $116(19.3 \%)$ & $133(22.1 \%)$ \\
\hline Low & $993(55.0 \%)$ & $377(62.7 \%)$ & $329(54.7 \%)$ & $287(47.8 \%)$ \\
\hline High & $469(26.0 \%)$ & $131(21.8 \%)$ & $157(26.1 \%)$ & $181(30.1 \%)$ \\
\hline \multicolumn{5}{|l|}{ Medication } \\
\hline Use of antihypertensive medication & $706(39.1 \%)$ & $183(30.4 \%)$ & $229(38.0 \%)$ & $294(48.9 \%)$ \\
\hline$\beta$-Blockers & $309(17.1 \%)$ & $91(13.5 \%)$ & $99(15.8 \%)$ & $133(22.1 \%)$ \\
\hline Calcium channel blockers & $163(9.0 \%)$ & $49(8.2 \%)$ & $57(9.5 \%)$ & $57(9.5 \%)$ \\
\hline ACE inhibitors & $224(12.4 \%)$ & $40(6.7 \%)$ & $69(11.5 \%)$ & $115(19.1 \%)$ \\
\hline Angiotensin II receptor blockers & $315(17.5 \%)$ & $86(14.3 \%)$ & $112(18.6 \%)$ & $117(19.5 \%)$ \\
\hline Diuretics & $285(15.8 \%)$ & $68(11.3 \%)$ & $98(16.3 \%)$ & $119(19.8 \%)$ \\
\hline Lipid-modifying medication & $651(36.1 \%)$ & $186(30.9 \%)$ & $205(34.1 \%)$ & $260(43.3 \%)$ \\
\hline 24-hour SBP, mm Hg & $120.0 \pm 11.6$ & $116.1 \pm 9.3$ & $119.6 \pm 11.1$ & $124.4 \pm 12.8$ \\
\hline 24-hour DBP, mm Hg & $74.3 \pm 7.1$ & $72.8 \pm 6.3$ & $74.2 \pm 6.9$ & $76.0 \pm 7.7$ \\
\hline \multicolumn{5}{|l|}{ BPV parameters } \\
\hline Within-visit systolic BPV, mm Hg & $4.6 \pm 2.8$ & $2.8 \pm 1.5$ & $4.4 \pm 2.0$ & $6.6 \pm 3.1$ \\
\hline Within-visit diastolic BPV, mm Hg & $2.5 \pm 1.7$ & $2.1 \pm 1.3$ & $2.4 \pm 1.5$ & $2.9 \pm 2.1$ \\
\hline 24-hour systolic BPV, mm Hg & $10.0 \pm 2.5$ & $8.2 \pm 1.4$ & $9.9 \pm 1.5$ & $12.0 \pm 2.7$ \\
\hline 24-hour diastolic BPV, mm Hg & $6.9 \pm 1.8$ & $6.2 \pm 1.4$ & $6.8 \pm 1.6$ & $7.8 \pm 2.1$ \\
\hline 7-day systolic BPV, mm Hg & $9.2 \pm 3.8$ & $6.9 \pm 1.7$ & $8.7 \pm 2.2$ & $12.0 \pm 4.7$ \\
\hline
\end{tabular}


Table 1. Continued

\begin{tabular}{|c|c|c|c|c|}
\hline \multirow{2}{*}{ Characteristic } & Memory Function & \multicolumn{3}{|c|}{ Tertiles of Composite Systolic Blood Pressure Variability } \\
\cline { 2 - 5 } & Population, $\mathrm{n}=1804$ & Tertile 1 (Low), $\mathrm{n}=601$ & Tertile 2 (Middle), $\mathrm{n}=602$ & Tertile 3 (High), $\mathrm{n}=601$ \\
\hline 7-day diastolic BPV, mm Hg & $5.7 \pm 2.9$ & $4.8 \pm 1.7$ & $5.4 \pm 1.8$ & $7.1 \pm 4.1$ \\
\hline Mental health and cognitive performance & \multicolumn{3}{|c|}{} \\
\hline Current major depressive episode & $64(3.6 \%)$ & $22(3.7 \%)$ & $16(2.7 \%)$ & $26(4.4 \%)$ \\
\hline Memory function & $0.00 \pm 1.00^{*}$ & $0.11 \pm 0.93$ & $0.03 \pm 0.98$ & $-0.13 \pm 1.03$ \\
\hline Information processing speed† & $0.00 \pm 1.00^{*}$ & $0.13 \pm 0.99$ & $-0.01 \pm 0.97$ & $-0.13 \pm 1.02$ \\
\hline Executive function $\ddagger$ & $0.00 \pm 1.00^{*}$ & $0.17 \pm 1.04$ & $-0.03 \pm 0.96$ & $-0.13 \pm 0.98$ \\
\hline
\end{tabular}

Data are presented as $n(\%)$, mean \pm SD, or median (interquartile range). ACE indicates angiotensin-converting enzyme; BMI, body mass index; BPV blood pressure variability; DBP, diastolic blood pressure; eGFR, estimated glomerular filtration rate; HDL, high-density lipoprotein; and SBP, systolic blood pressure.

*Mean of zero and SD of 1 by definition, see Methods section.

†Value shown for individuals with complete information processing speed data.

fValue shown for individuals with complete executive function data.

LDL (low-density lipoprotein) cholesterol, triglycerides, fasting glucose, postload glucose, and glycosylated hemoglobin were determined as described elsewhere. ${ }^{20}$ Glucose metabolism status was categorized into normal glucose metabolism, prediabetes (impaired fasting glucose or impaired glucose tolerance), and T2DM, according to the World Health Organization 2006 criteria. ${ }^{28}$ Estimated glomerular filtration rate was computed with the CKD-EPI (Chronic Kidney Disease Epidemiology Collaboration) formula, using serum creatinine and cystatin C. ${ }^{29}$ Information on the use of lipid-modifying and antihypertensive medication were collected during an interview. A current major depressive episode was assessed by the MiniInternational Neuropsychiatric Interview. ${ }^{30}$

\section{Statistical Analysis}

All data were analyzed using IBM SPSS software version 23.0 for Windows (IBM Corp, Somers, NY). Data are presented as n (\%), mean $\pm \mathrm{SD}$, or median (interquartile range). We constructed tertiles of composite systolic and diastolic BPV. Associations between composite systolic and diastolic BPV and the composite scores of cognitive performance domains were examined with the use of multiple linear regression (lowest BPV tertile: reference category). Model 1 was adjusted for age, sex, and glucose metabolism status. Model 2 was additionally adjusted for 24-hour mean systolic or diastolic BP (where appropriate). Model 3 was additionally adjusted for lifestyle factors (ie, BMI, alcohol consumption, smoking status, and educational level). Model 4 was additionally adjusted for CVD risk factors (ie, estimated glomerular filtration rate, total-to-high density lipoprotein cholesterol ratio, triglycerides, lipid-modifying, and antihypertensive medication classes [ $\beta$-blockers, calcium channel blockers, ACE (angiotensin-converting enzyme) inhibitors, angiotensin II receptor blockers, and diuretics separately]). Model 5 was additionally adjusted for prior CVD and current major depressive episode. Several additional analyses were performed. First, we included interaction terms in model 5 to examine whether any associations were modified by age, sex, or glucose metabolism status. Second, we additionally adjusted for moderate-to-vigorous physical activity and waist circumference or waist-to-hip ratio instead of BMI. Third, we evaluated the association between each individual BPV-index (ie, within-visit, 24-hour and 7-day BPV) and the cognitive performance domains separately. A 2 -sided $P$ value of $<0.05$ was considered statistically significant, except for the interaction analyses, where we used $P<0.10$.

\section{Results}

\section{Study Population}

Figure 1 shows the delineation of our study population. Participants with missing data had a higher BMI, lower total cholesterol levels, higher 7-day systolic BPV, and higher 24-hour and 7-day diastolic BPV, and lower MF scores, and IPS than those with complete data (Table S1 in the online-only Data Supplement).

Table 1 shows the characteristics of the study population with complete MF data according to tertiles of composite BPV (tertile 1: lowest BPV). In general, participants with the highest as compared to the lowest BPV were older, more often women, received lower education more often, had a worse CVD risk profile, and more often used antihypertensive medication. In addition, participants with the highest as compared to the lowest BPV had lower scores on cognitive performance.

\section{Systolic BPV and Cognitive Performance}

After adjustment for age, sex, glucose metabolism status (model 1), and 24-hour mean systolic BP (model 2), high systolic BPV was statistically significantly associated with a lower MF as compared to the lowest tertile of systolic BPV (regression coefficient [ $\beta$, as SD difference] and $95 \%$ CI, -0.118 ; -0.226 to -0.010 ; Table 2; Figure 2). No statistically significant associations were observed with IPS $(-0.045 ; 95 \% \mathrm{CI},-0.519$ to 0.062$)$ and $\mathrm{EF}(-0.082 ; 95 \%$ $\mathrm{CI},-0.195$ to 0.030$)$. After further adjustment for estimated glomerular filtration rate, total-to-HDL cholesterol ratio, triglycerides, antihypertensive and lipid-modifying medication (model 4), prior CVD, and current depression (model 5), the associations attenuated and MF was lower in individuals with a high systolic BPV as compared to those with low systolic BPV, but did not reach statistical significance $(-0.106 ; 95 \% \mathrm{CI},-0.213$ to 0.001$)$. In addition, systolic BPV was not statistically significantly associated with IPS $(-0.039 ; 95 \% \mathrm{CI},-0.142$ to 0.064$)$ and EF $(-0.087$; $95 \% \mathrm{CI},-0.195$ to 0.022$)$.

\section{Diastolic BPV and Cognitive Performance}

After adjustment for the covariates of model 2, and with the lowest tertile of diastolic BPV as reference category, high diastolic BPV was statistically significantly associated with lower performance in all cognitive domains: MF $(-0.123$; $95 \% \mathrm{CI},-0.226$ to -0.019$)$, IPS $(-0.137 ; 95 \% \mathrm{CI},-0.239$ to 
Table 2. Associations Between Systolic Blood Pressure Variability and Various Domains of Cognitive Performance

\begin{tabular}{|c|c|c|c|c|c|c|c|}
\hline \multirow[b]{3}{*}{ Model } & \multirow[b]{3}{*}{ Composite sBPV } & \multicolumn{6}{|c|}{ Cognitive Performance Domains } \\
\hline & & \multicolumn{2}{|l|}{ Memory Function } & \multicolumn{2}{|c|}{ Information Processing Speed } & \multicolumn{2}{|l|}{ Executive Function } \\
\hline & & $\beta(95 \% \mathrm{Cl})$ & $P$ Value & $\beta(95 \% \mathrm{Cl})$ & $P$ Value & $\beta(95 \% \mathrm{Cl})$ & $P$ Value \\
\hline \multicolumn{8}{|l|}{ Crude } \\
\hline & Low & Reference & & Reference & & Reference & \\
\hline & Middle & -0.084 ( -0.197 to 0.029$)$ & 0.15 & $-0.134(-0.247$ to -0.022$)$ & 0.019 & $-0.195(-0.308$ to -0.082$)$ & 0.001 \\
\hline & High & $-0.234(-0.347$ to -0.121$)$ & $<0.001$ & $-0.271(-0.383$ to -0.158$)$ & $<0.001$ & $-0.287(-0.400$ to -0.174$)$ & $<0.001$ \\
\hline \multicolumn{8}{|l|}{1} \\
\hline & Low & Reference & & Reference & & Reference & \\
\hline & Middle & $-0.005(-0.106$ to 0.097$)$ & 0.93 & $0.002(-0.099$ to 0.102$)$ & 0.98 & -0.076 ( -0.181 to 0.029$)$ & 0.16 \\
\hline & High & $-0.092(-0.196$ to 0.011$)$ & 0.08 & $-0.021(-0.123$ to 0.081$)$ & 0.69 & -0.069 ( -0.177 to 0.038$)$ & 0.21 \\
\hline \multicolumn{8}{|l|}{2} \\
\hline & Low & Reference & & Reference & & Reference & \\
\hline & Middle & $-0.016(-0.118$ to 0.086$)$ & 0.76 & -0.009 (-0.110 to 0.092$)$ & 0.86 & -0.082 ( -0.188 to 0.024$)$ & 0.13 \\
\hline & High & $-0.118(-0.226$ to -0.010$)$ & 0.033 & $-0.045(-0.151$ to 0.062$)$ & 0.41 & $-0.082(-0.195$ to 0.030$)$ & 0.15 \\
\hline \multicolumn{8}{|l|}{3} \\
\hline & Low & Reference & & Reference & & Reference & \\
\hline & Middle & $-0.004(-0.098$ to 0.096$)$ & 0.94 & $0.010(-0.087$ to 0.107$)$ & 0.84 & -0.064 ( -0.165 to 0.038$)$ & 0.22 \\
\hline & High & $-0.117(-0.210$ to -0.011$)$ & 0.030 & $-0.040(-0.143$ to 0.062$)$ & 0.44 & $-0.085(-0.192$ to 0.023$)$ & 0.12 \\
\hline \multicolumn{8}{|l|}{4} \\
\hline & Low & Reference & & Reference & & Reference & \\
\hline & Middle & $0.002(-0.099$ to 0.102$)$ & 0.97 & $0.010(-0.086$ to 0.107$)$ & 0.83 & -0.066 ( -0.168 to 0.036$)$ & 0.20 \\
\hline & High & $-0.105(-0.212$ to 0.002$)$ & 0.06 & $-0.036(-0.139$ to 0.067$)$ & 0.49 & $-0.084(-0.193$ to 0.025$)$ & 0.13 \\
\hline \multicolumn{8}{|l|}{5} \\
\hline & Low & Reference & & Reference & & Reference & \\
\hline & Middle & $0.000(-0.094$ to 0.098$)$ & 0.97 & $0.006(-0.091$ to 0.102$)$ & 0.91 & $-0.072(-0.174$ to 0.030$)$ & 0.16 \\
\hline & High & $-0.106(-0.213$ to 0.001$)$ & 0.05 & $-0.039(-0.142$ to 0.064$)$ & 0.46 & $-0.087(-0.195$ to 0.022$)$ & 0.11 \\
\hline
\end{tabular}

Regression coefficients $(\beta)$ represent the SD difference in the cognitive domain scores as compared with participants with a low systolic BPV (lowest tertile of BPV). Model 1: age, sex, glucose metabolism status. Model 2: model 1+mean 24-h systolic blood pressure. Model 3: model 2+BMl, smoking behavior, alcohol use, educational level. Model 4: model 3+eGFR, total-to-high density lipoprotein cholesterol ratio, triglycerides, (individual classes of) antihypertensive medication, lipidmodifying medication. Model 5: model 4+prior cardiovascular disease, current depression. BMI indicates body mass index; BPV, blood pressure variability; eGFR, estimated glomerular filtration rate; and SBPV, systolic blood pressure variability.

$-0.035])$, and EF ( -0.128 ; $95 \%$ CI, -0.235 to -0.021 ; Table 2; Figure 3). After adjustment for the covariates of model 5, the associations attenuated but remained statistically significant for IPS $(-0.101 ; 95 \% \mathrm{CI},-0.200$ to -0.002$)$ and $\mathrm{EF}(-0.115$; $95 \% \mathrm{CI},-0.220$ to -0.011$)$. In addition, MF was lower in individuals with high diastolic BPV as compared to those with low diastolic BPV but did not reach statistical significance (-0.094; $95 \%$ CI, -0.197 to 0.009$)$.

\section{Additional Analyses}

Age, sex, and glucose metabolism did modify some associations between systolic or diastolic BPV and cognitive performance (Table S2). We did not detect a consistent interaction pattern over the domains of cognitive performance and, therefore, did not stratify the analyses.

After additional adjustment for moderate-to-vigorous physical activity, and waist circumference or waist-to-hip ratio instead of BMI, the associations between systolic or diastolic BPV and cognitive performance did not materially change (Tables S3-S9).

When we analyzed the individual systolic BPV-indices separately, within-visit and 24-hour systolic BPV and cognitive performance were not statistically significantly associated, whereas a high 7-day systolic BPV was statistically significantly associated with a lower performance in all cognitive domains as compared to the lowest tertile of 7-day systolic BPV. When we analyzed the individual diastolic BPV-indices separately, middle within-visit diastolic BPV was statistically significantly associated with lower EF as compared to the lowest tertile of within-visit diastolic BPV, high 24-hour diastolic BPV was statistically significantly associated with lower performance in all cognitive domains as compared to the lowest tertile of 24-hour diastolic BPV, and middle and high 7-day diastolic BPV was statistically significantly associated with 




Figure 2. Estimated means of cognitive performance domains according to tertiles of systolic blood pressure variability (sBPV) after adjustment for the covariates of model 2. T1, T2, and T3 indicate tertiles with low, middle and high sBPV respectively. EF indicates executive functioning; IPS, information processing speed; and MF, memory function. Error bars represent $95 \% \mathrm{Cl}$. *Statistically significant difference as compared to the lowest tertile (T1).

lower IPS and EF as compared to the lowest tertile of 7-day diastolic BPV (Tables S9-S14).

\section{Discussion}

Our study, performed in 40- to 75-year-old individuals, showed that greater very short-term to mid-term systolic and diastolic BPV differentially affects various domains of cognitive performance. First, greater diastolic BPV was associated with both lower IPS and EF and was marginally associated with lower MF. Second, greater systolic BPV was only marginally associated with a lower MF. All these associations were independent of mean systolic or diastolic BP, lifestyle factors, educational level, and cardiovascular risk factors. The observed effects are equivalent to $\approx 3$ additional years of general aging. In terms of risk factors, in the light of previous studies performed in The Maastricht Study, the detrimental

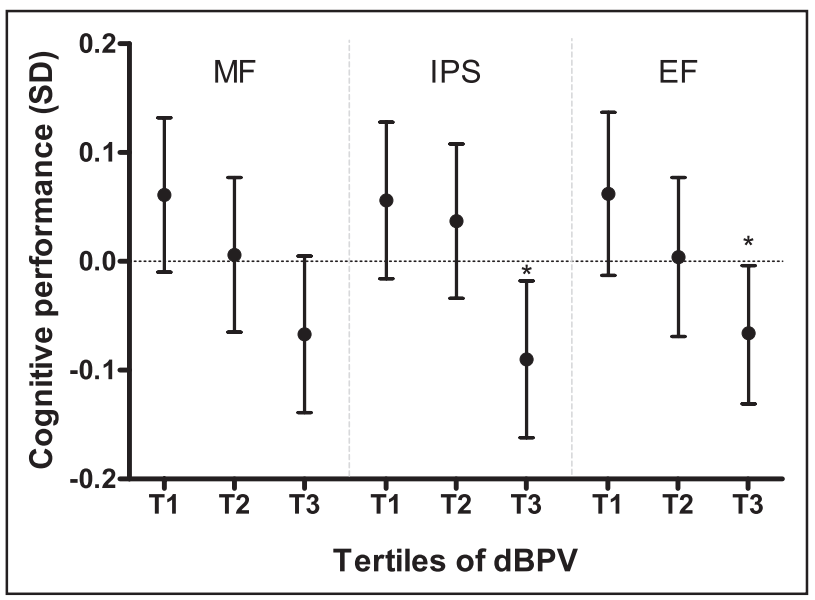

Figure 3. Estimated means of cognitive performance domains according to tertiles of diastolic blood pressure variability (dBPV) after adjustment for the covariates of model 2. T1, T2, and T3 indicate tertiles with low, middle and high dBPV respectively. EF indicates executive functioning; IPS, information processing speed; and MF, memory function. Error bars represent $95 \% \mathrm{Cl}$. *Statistically significant difference as compared to the lowest tertile (T1). effects of greater systolic and diastolic BPV on cognitive performance are similar to the effects of the presence of microalbuminuria $^{31}$ and greater carotid arterial stiffness. ${ }^{32}$

Our findings are largely in line with previous studies, where greater systolic or diastolic BPV were associated with lower cognitive performance. However, previous studies have assessed only global cognitive performance, such as the MiniMental State Exam ${ }^{15}$ or tested only one domain of cognitive performance. ${ }^{19}$ Other studies have investigated specific study populations, such as individuals who already had dementia ${ }^{10}$ or old to very old individuals. ${ }^{11-14}$ In addition, many studies have investigated whether long-term BPV (ie, visit-to-visit) affects cognitive performance..$^{7-9,12,33}$ Our study thereby adds novelty to the literature, as our study was performed in communitydwelling individuals and applied an extensive cognitive test battery. In addition, we have shown that not only greater longterm BPV affects cognitive performance, but greater very short-term to mid-term diastolic BPV does so as well.

Interestingly, we observed a more pronounced effect of greater diastolic BPV on lower cognitive performance than systolic BPV. This may be explained by several mechanisms. First, diastolic BP is the main determinant of mean arterial pressure, and as such, excessive variation in diastolic BP may hamper perfusion and induce cerebral ischemia. Indeed, previous studies have shown that impaired cerebral blood flow may play a role in the progression of cerebral small vessel disease, ${ }^{34}$ and impaired cerebral blood flow itself has been strongly associated with incident dementia. ${ }^{35}$ Second, in a previous report, we observed that greater systolic BPV was associated with arterial stiffening, whereas diastolic BPV was not. ${ }^{36}$ Indeed, it has been reported that arterial stiffening (carotid-to-femoral, brachial-to-ankle, and local carotid) was associated with cerebral small vessel disease, potentially via an increased pulsatile pressure load. However, associations between arterial stiffening and cognitive impairment were relatively weak, which suggests that additional factors other than cerebral small vessel disease alone may explain the mechanisms underlying cognitive impairment. ${ }^{37}$

We, therefore, speculate that greater systolic BPV may specifically cause more macrovascular damage (eg, aortic stiffening), whereas diastolic BPV is causing more microvascular damage (eg, cerebral small vessel disease).

We observed that greater systolic BPV was only marginally associated with MF, but not with IPS and EF, as opposed to diastolic BPV, which had an effect on all cognitive domains. We hypothesize that this might be because of the increased vulnerability to ischemia of watershed areas (eg, the parietotemporal area), where perfusion is already poor. ${ }^{38}$ Peaks in systolic BP may then induce autoregulatory vasoconstriction ${ }^{6}$ and may lead to ischemia preferentially in the temporal areas, such as the hippocampus, which is an important brain region for memory consolidation. ${ }^{39}$ Greater diastolic BPV, however, may reduce cerebral perfusion pressure in many brain regions and may, therefore, affect multiple cognitive functions.

The strengths of our study include the use of multiple BPVindices and the well-characterized, large study population, which allowed us to adjust for a large series of confounders. In fact, model 5 may represent an overadjusted model, as depression, for instance, may lie in the causal pathway between 
Table 3. Associations Between Diastolic Blood Pressure Variability and Various Domains of Cognitive Performance

\begin{tabular}{|c|c|c|c|c|c|c|c|}
\hline \multirow[b]{3}{*}{ Model } & \multirow[b]{3}{*}{ Composite dBPV } & \multicolumn{6}{|c|}{ Cognitive Performance Domains } \\
\hline & & \multicolumn{2}{|l|}{ Memory Function } & \multicolumn{2}{|c|}{ Information Processing Speed } & \multicolumn{2}{|l|}{ Executive Function } \\
\hline & & $\beta(95 \% \mathrm{Cl})$ & $P$ Value & $\beta(95 \% \mathrm{Cl})$ & $P$ Value & $\beta(95 \% \mathrm{Cl})$ & $P$ Value \\
\hline \multicolumn{8}{|l|}{ Crude } \\
\hline & Low & Reference & & Reference & & Reference & \\
\hline & Middle & $-0.084(-0.197$ to 0.029$)$ & 0.15 & $-0.046(-0.159$ to 0.067$)$ & 0.42 & $-0.110(-0.223$ to 0.004$)$ & 0.06 \\
\hline & High & $-0.219(-0.332$ to -0.106$)$ & $<0.001$ & $-0.269(-0.382$ to -0.156$)$ & $<0.001$ & $-0.226(-0.379$ to -0.153$)$ & $<0.001$ \\
\hline \multicolumn{8}{|l|}{1} \\
\hline & Low & Reference & & Reference & & Reference & \\
\hline & Middle & $-0.040(-0.140$ to 0.060$)$ & 0.44 & $0.017(-0.083$ to 0.116$)$ & 0.74 & $-0.054(-0.158$ to 0.051$)$ & 0.31 \\
\hline & High & $-0.111(-0.212$ to -0.009$)$ & 0.032 & $-0.108(-0.209$ to -0.008$)$ & 0.034 & $-0.121(-0.227$ to -0.016$)$ & 0.024 \\
\hline \multicolumn{8}{|l|}{2} \\
\hline & Low & Reference & & Reference & & Reference & \\
\hline & Middle & $-0.047(-0.149$ to 0.054$)$ & 0.36 & -0.001 ( -0.101 to 0.099$)$ & 0.98 & $-0.058(-0.163$ to 0.047$)$ & 0.28 \\
\hline & High & $-0.123(-0.226$ to -0.019$)$ & 0.020 & $-0.137(-0.239$ to -0.035$)$ & 0.009 & $-0.128(-0.235$ to -0.021$)$ & 0.019 \\
\hline \multicolumn{8}{|l|}{3} \\
\hline & Low & Reference & & Reference & & Reference & \\
\hline & Middle & $-0.036(-0.135$ to 0.063$)$ & 0.48 & $0.019(-0.077$ to 0.114$)$ & 0.70 & $-0.040(-0.141$ to 0.060$)$ & 0.43 \\
\hline & High & $-0.109(-0.211$ to -0.007$)$ & 0.036 & $-0.111(-0.210$ to -0.013$)$ & 0.026 & $-0.114(-0.217$ to -0.010$)$ & 0.031 \\
\hline \multicolumn{8}{|l|}{4} \\
\hline & Low & Reference & & Reference & & Reference & \\
\hline & Middle & $-0.037(-0.137$ to 0.062$)$ & 0.46 & $0.015(-0.081$ to 0.111$)$ & 0.76 & $-0.048(-0.148$ to 0.053$)$ & 0.35 \\
\hline & High & $-0.095(-0.198$ to 0.008$)$ & 0.07 & $-0.101(-0.200$ to -0.002$)$ & 0.046 & $-0.113(-0.217$ to -0.009$)$ & 0.033 \\
\hline \multicolumn{8}{|l|}{5} \\
\hline & Low & Reference & & Reference & & Reference & \\
\hline & Middle & $-0.037(-0.136$ to 0.063$)$ & 0.47 & $0.016(-0.079$ to 0.112$)$ & 0.74 & $-0.048(-0.149$ to 0.052$)$ & 0.35 \\
\hline & High & $-0.094(-0.197$ to 0.009$)$ & 0.07 & $-0.101(-0.200$ to -0.002$)$ & 0.046 & $-0.115(-0.220$ to -0.011$)$ & 0.030 \\
\hline
\end{tabular}

Regression coefficients $(\beta)$ represent the SD difference in the cognitive domain scores as compared with participants with a low diastolic BPV (lowest tertile of BPV). Model 1: age, sex, glucose metabolism status. Model 2: model 1+mean 24-h diastolic blood pressure. Model 3: model 2+BMl, smoking behavior, alcohol use, educational level. Model 4: model 3+eGFR, total-to-high density lipoprotein cholesterol ratio, triglycerides, (individual classes of) antihypertensive medication, lipidmodifying medication. Model 5: model 4+prior cardiovascular disease, current depression. BMI indicates body mass index; BPV, blood pressure variability; dBPV, diastolic blood pressure variability; and eGFR, estimated glomerular filtration rate.

greater BPV and lower cognitive performance. Nonetheless, the effects of BPV on cognitive performance changed minimally after model 3 and 4 .

There were several limitations of this study. First, the cross-sectional nature of this study implies that any causal inference should be made with caution. The reverse association may hold true as well, as it can be hypothesized that lower cognitive performance could lead to worse medication adherence, which may then cause greater BPV ${ }^{40}$ Second, the design of this study required the population to be enriched with T2DM, and it might be argued that adjustment for glucose metabolism status may then not be sufficient. However, there was no consistent interaction pattern with glucose metabolism status, age, or sex. Third, participants with and without missing data differed. This may have led to an underestimation of our effect, as participants with missing data had a more adverse (cardiovascular) risk profile. Fourth, we cannot exclude the possibility of residual confounding, as, for example, family history of dementia ${ }^{41,42}$ was not available. Fifth, the use of a composite BPV-index assumes that the individual $\mathrm{BPV}$-indices share the same underlying pathophysiological mechanisms in lowering cognitive performance. Our results have shown that all individual BPV-indices were directionally similarly associated with cognitive performance, which implies that excessive BPV measured in any time frame, despite its different determinants, may damage the brain via similar mechanisms leading to lower cognitive performance. This justifies our approach with regard to the construction of a composite BPV-index.

\section{Perspectives}

Greater very short-term to mid-term diastolic and, to a lesser extent, systolic BPV may be a modifiable risk factor for cognitive deterioration in 40- to 75-year old, community-dwelling 
individuals. The effects of greater BPV on cognitive performance were equivalent to 3 additional years of aging. In terms of risk factors, these effects were similar to the presence of microalbuminuria and carotid stiffness. Future research should focus on intervention trials dedicated to lowering BPV, and investigate whether it has a positive effect on preserving cognitive performance. If lowering BPV would indeed be beneficial, it could delay, or even prevent, cognitive decline in mid to later life.

\section{Sources of Funding}

This study was supported by the European Regional Development Fund via OP-Zuid, the Province of Limburg, the Dutch Ministry of Economic Affairs (grant 310.041), Stichting De Weijerhorst (Maastricht, the Netherlands), the Pearl String Initiative Diabetes (Amsterdam, the Netherlands), Cardiovascular Research Institute Maastricht School for Cardiovascular Diseases (Maastricht, the Netherlands), Stichting Annadal (Maastricht, the Netherlands), Health Foundation Limburg (Maastricht, the Netherlands) and by unrestricted grants from Janssen-Cilag B.V. (Tilburg, the Netherlands), Novo Nordisk Farma B.V. (Alphen aan den Rijn, the Netherlands) and Sanofi-Aventis Netherlands B.V. (Gouda, the Netherlands).

\section{Disclosures}

None.

\section{References}

1. Oeppen J, Vaupel JW. Demography. Broken limits to life expectancy. Science. 2002;296:1029-1031. doi: 10.1126/science.1069675

2. Plassman BL, Langa KM, Fisher GG, Heeringa SG, Weir DR, Ofstedal MB, Burke JR, Hurd MD, Potter GG, Rodgers WL, Steffens DC, McArdle JJ, Willis RJ, Wallace RB. Prevalence of cognitive impairment without dementia in the United States. Ann Intern Med. 2008;148:427-434.

3. Webb AJ, Fischer U, Mehta Z, Rothwell PM. Effects of antihypertensivedrug class on interindividual variation in blood pressure and risk of stroke: a systematic review and meta-analysis. Lancet. 2010;375:906-915. doi: 10.1016/S0140-6736(10)60235-8

4. Mitchell GF. Effects of central arterial aging on the structure and function of the peripheral vasculature: implications for end-organ damage. $J$ Appl Physiol (1985). 2008;105:1652-1660. doi: 10.1152/japplphysiol. 90549.2008

5. Rickards CA, Tzeng YC. Arterial pressure and cerebral blood flow variability: friend or foe? A review. Front Physiol. 2014;5:120. doi: 10.3389/fphys.2014.00120

6. Rothwell PM. Limitations of the usual blood-pressure hypothesis and importance of variability, instability, and episodic hypertension. Lancet. 2010;375:938-948. doi: 10.1016/S0140-6736(10)60309-1

7. Qin B, Viera AJ, Muntner P, Plassman BL, Edwards LJ, Adair LS, Popkin BM, Mendez MA. Visit-to-visit variability in blood pressure is related to late-life cognitive decline. Hypertension. 2016;68:106-113. doi: 10.1161/HYPERTENSIONAHA.116.07494

8. Sabayan B, Wijsman LW, Foster-Dingley JC, Stott DJ, Ford I, Buckley BM, Sattar N, Jukema JW, van Osch MJ, van der Grond J, van Buchem MA, Westendorp RG, de Craen AJ, Mooijaart SP. Association of visit-to-visit variability in blood pressure with cognitive function in old age: prospective cohort study. BMJ. 2013;347:f4600. doi: 10.1136/bmj.f4600

9. Yano Y, Ning H, Allen N, Reis JP, Launer LJ, Liu K, Yaffe K, Greenland P, Lloyd-Jones DM. Long-term blood pressure variability throughout young adulthood and cognitive function in midlife: the Coronary Artery Risk Development in Young Adults (CARDIA) study. Hypertension. 2014;64:983-988. doi: 10.1161/HYPERTENSIONAHA.114.03978

10. Epstein NU, Lane KA, Farlow MR, Risacher SL, Saykin AJ, Gao S; Alzheimer's Disease Neuroimaging Initiative. Cognitive dysfunction and greater visit-to-visit systolic blood pressure variability. J Am Geriatr Soc. 2013;61:2168-2173. doi: 10.1111/jgs. 12542

11. Nagai M, Hoshide S, Nishikawa M, Masahisa S, Kario K. Visit-to-visit blood pressure variability in the elderly: associations with cognitive impairment and carotid artery remodeling. Atherosclerosis. 2014;233:19-26. doi: 10.1016/j.atherosclerosis.2013.11.071
12. Nagai M, Hoshide S, Ishikawa J, Shimada K, Kario K. Visit-to-visit blood pressure variations: new independent determinants for cognitive function in the elderly at high risk of cardiovascular disease. J Hypertens. 2012;30:1556-1563. doi: 10.1097/HJH.0b013e3283552735

13. Sakakura K, Ishikawa J, Okuno M, Shimada K, Kario K. Exaggerated ambulatory blood pressure variability is associated with cognitive dysfunction in the very elderly and quality of life in the younger elderly. $A m$ J Hypertens. 2007;20:720-727. doi: 10.1016/j.amjhyper.2007.02.001

14. Yamaguchi Y, Wada M, Sato H, Nagasawa H, Koyama S, Takahashi Y, Kawanami T, Kato T. Impact of ambulatory blood pressure variability on cerebral small vessel disease progression and cognitive decline in community-based elderly Japanese. Am J Hypertens. 2014;27:1257-1267. doi: 10.1093/ajh/hpu045

15. Matsumoto A, Satoh M, Kikuya M, et al. Day-to-day variability in home blood pressure is associated with cognitive decline: the Ohasama study. Hypertension. 2014;63:1333-1338. doi: 10.1161/HYPERTENSIONAHA. 113.01819

16. McDonald C, Pearce MS, Kerr SR, Newton JL. Blood pressure variability and cognitive decline in older people: a 5-year longitudinal study. $J$ Hypertens. 2017;35:140-147. doi: 10.1097/HJH.0000000000001120

17. Oishi E, Ohara T, Sakata S, Fukuhara M, Hata J, Yoshida D, Shibata M, Ohtsubo T, Kitazono T, Kiyohara Y, Ninomiya T. Day-to-day blood pressure variability and risk of dementia in a general Japanese elderly population: the Hisayama Study. Circulation. 2017;136:516-525. doi: 10.1161/CIRCULATIONAHA.116.025667

18. Crichton GE, Elias MF, Dore GA, Torres RV, Robbins MA. Measurementto-measurement blood pressure variability is related to cognitive performance: the Maine Syracuse study. Hypertension. 2014;64:1094-1101. doi: 10.1161/HYPERTENSIONAHA.114.04282

19. Gutierrez J, Marshall RS, Lazar RM. Indirect measures of arterial stiffness and cognitive performance in individuals without traditional vascular risk factors or disease. JAMA Neurol. 2015;72:309-315. doi: $10.1001 /$ jamaneurol.2014.3873

20. Schram MT, Sep SJ, van der Kallen CJ, Dagnelie PC, Koster A, Schaper N, Henry RM, Stehouwer CD. The Maastricht Study: an extensive phenotyping study on determinants of type 2 diabetes, its complications and its comorbidities. Eur J Epidemiol. 2014;29:439-451. doi: 10.1007/s10654-014-9889-0

21. Zhou TL, Kroon AA, Reesink KD, Schram MT, Koster A, Schaper NC, Dagnelie PC, van der Kallen CJH, Sep SJS, Stehouwer CDA, Henry RMA. Blood pressure variability in individuals with and without (pre) diabetes: the Maastricht Study. J Hypertens. 2018;36:259-267. doi: 10.1097/HJH.0000000000001543

22. O'Brien PC. Procedures for comparing samples with multiple endpoints. Biometrics. 1984;40:1079-1087.

23. Pocock SJ, Geller NL, Tsiatis AA. The analysis of multiple endpoints in clinical trials. Biometrics. 1987;43:487-498.

24. Van der Elst W, van Boxtel MP, van Breukelen GJ, Jolles J. Rey's verbal learning test: normative data for 1855 healthy participants aged 24-81 years and the influence of age, sex, education, and mode of presentation. J Int Neuropsychol Soc. 2005;11:290-302. doi: 10.1017/S1355617705050344

25. Van der Elst W, Van Boxtel MP, Van Breukelen GJ, Jolles J. The Stroop color-word test: influence of age, sex, and education; and normative data for a large sample across the adult age range. Assessment. 2006;13:62-79. doi: 10.1177/1073191105283427

26. Van der Elst W, Van Boxtel MP, Van Breukelen GJ, Jolles J. The concept shifting test: adult normative data. Psychol Assess. 2006;18:424-432. doi: 10.1037/1040-3590.18.4.424

27. van der Elst W, van Boxtel MP, van Breukelen GJ, Jolles J. The Letter Digit Substitution Test: normative data for 1,858 healthy participants aged 24-81 from the Maastricht Aging Study (MAAS): influence of age, education, and sex. J Clin Exp Neuropsychol. 2006;28:998-1009. doi: $10.1080 / 13803390591004428$

28. World Health Organization. Definition and Diagnosis of Diabetes Mellitus and Intermediate Hyperglycemia: Report of a WHO/IDF Consultation. Geneva, Switzerland: World Health Organization; 2006.

29. Inker LA, Schmid CH, Tighiouart H, Eckfeldt JH, Feldman HI, Greene T, Kusek JW, Manzi J, Van Lente F, Zhang YL, Coresh J, Levey AS; CKD-EPI Investigators. Estimating glomerular filtration rate from serum creatinine and cystatin C. N Engl J Med. 2012;367:20-29. doi: 10.1056/NEJMoa1114248

30. Sheehan DV, Lecrubier Y, Sheehan KH, Amorim P, Janavs J, Weiller E, Hergueta T, Baker R, Dunbar GC. The mini-international neuropsychiatric interview (m.I.N.I.): The development and validation of a structured 
diagnostic psychiatric interview for dsm-iv and icd-10. J Clin Psychiatry. 1998;59(suppl 20):22-33;quiz 34-57

31. Martens RJ, Kooman JP, Stehouwer CD, Dagnelie PC, van der Kallen CJ, Koster A, Kroon AA, Leunissen KM, Nijpels G, van der Sande FM, Schaper NC, Sep SJ, van Boxtel MP, Schram MT, Henry RM. Estimated GFR, albuminuria, and cognitive performance: the Maastricht Study. Am J Kidney Dis. 2017;69:179-191. doi: 10.1053/j.ajkd.2016.04.017

32. Geijselaers SL, Sep SJ, Schram MT, van Boxtel MP, van Sloten TT, Henry RM, Reesink KD, Kroon AA, Koster A, Schaper NC, Dagnelie PC, van der Kallen CJ, Biessels GJ, Stehouwer CD. Carotid stiffness is associated with impairment of cognitive performance in individuals with and without type 2 diabetes. The Maastricht Study. Atherosclerosis. 2016;253:186193. doi: 10.1016/j.atherosclerosis.2016.07.912

33. Tully PJ, Debette S, Tzourio C. The association between systolic blood pressure variability with depression, cognitive decline and white matter hyperintensities: the 3C Dijon MRI study. Psychol Med. 2018;48:14441453. doi: $10.1017 / \mathrm{S} 0033291717002756$

34. Smith EE, Beaudin AE. New insights into cerebral small vessel disease and vascular cognitive impairment from MRI. Curr Opin Neurol. 2018;31:36-43. doi: 10.1097/WCO.0000000000000513

35. Wolters FJ, Zonneveld HI, Hofman A, van der Lugt A, Koudstaal PJ, Vernooij MW, Ikram MA; Heart-Brain Connection Collaborative Research Group. Cerebral perfusion and the risk of dementia: a population-based study. Circulation. 2017;136:719-728. doi: 10.1161/CIRCULATIONAHA.117.027448

36. Zhou TL, Henry RMA, Stehouwer CDA, van Sloten TT, Reesink $\mathrm{KD}$, Kroon AA. Blood pressure variability, arterial stiffness, and arterial remodeling. Hypertension. 2018;72:1002-1010. doi: 10.1161/HYPERTENSIONAHA.118.11325

37. van Sloten TT, Protogerou AD, Henry RM, Schram MT, Launer LJ, Stehouwer CD. Association between arterial stiffness, cerebral small vessel disease and cognitive impairment: a systematic review and meta-analysis. Neurosci Biobehav Rev. 2015;53:121-130. doi: 10.1016/j.neubiorev.2015.03.011

38. Moody DM, Brown WR, Challa VR, Ghazi-Birry HS, Reboussin DM. Cerebral microvascular alterations in aging, leukoaraiosis, and Alzheimer's disease. Ann N Y Acad Sci. 1997;826:103-116.

39. Suter OC, Sunthorn T, Kraftsik R, Straubel J, Darekar P, Khalili K, Miklossy J. Cerebral hypoperfusion generates cortical watershed microinfarcts in Alzheimer disease. Stroke. 2002;33:1986-1992.

40. Kronish IM, Lynch AI, Oparil S, Whittle J, Davis BR, Simpson LM, Krousel-Wood M, Cushman WC, Chang TI, Muntner P. The association between antihypertensive medication nonadherence and visit-to-visit variability of blood pressure: findings from the Antihypertensive and Lipid-Lowering Treatment to Prevent Heart Attack Trial. Hypertension. 2016;68:39-45. doi: 10.1161/HYPERTENSIONAHA.115.06960

41. Donix M, Ercoli LM, Siddarth P, Brown JA, Martin-Harris L, Burggren AC, Miller KJ, Small GW, Bookheimer SY. Influence of Alzheimer disease family history and genetic risk on cognitive performance in healthy middle-aged and older people. Am J Geriatr Psychiatry. 2012;20:565573. doi: 10.1097/JGP.0b013e3182107e6a

42. Locke DE, Ivnik RJ, Cha RH, Knopman DS, Tangalos EG, Boeve BF, Petersen RC, Smith GE. Age, family history, and memory and future risk for cognitive impairment. J Clin Exp Neuropsychol. 2009;31:111-116. doi: $10.1080 / 13803390802020443$

\section{Novelty and Significance}

\section{What Is New?}

- An important consequence of the globally increasing life expectancy will be that an increasing number of individuals will face age-related health problems, of which cognitive impairment is a major problem. To delay or prevent cognitive impairment, we investigated the association between very short- to mid-term blood pressure variability and cognitive performance.

\section{What Is Relevant?}

- Greater very short- to mid-term systolic and diastolic blood pressure variability (BPV) were differentially associated with lower cognitive performance, specifically:
- Greater diastolic BPV was associated with both lower information processing speed and executive function and was marginally associated with lower memory function.

- Greater systolic BPV was only marginally associated with a lower memory function.

\section{Summary}

Greater very short-term to mid-term diastolic, and to a lesser extent, systolic BPV are associated with lower cognitive performance. These effects were comparable to 3 additional years of aging. In short, these findings suggest that very short- to mid-term BPV may be a modifiable risk factor for cognitive impairment. 